\title{
The discovery and importance of genomic imprinting
}

Abstract The discovery of genomic imprinting by Davor Solter, Azim Surani and co-workers in the mid-1980s has provided a foundation for the study of epigenetic inheritance and the epigenetic control of gene activity and repression, especially during development. It also has shed light on a range of diseases, including both rare genetic disorders and common diseases. This article is being published to celebrate Solter and Surani receiving a 2018 Canada Gairdner International Award "for the discovery of mammalian genomic imprinting that causes parent-of-origin specific gene expression and its consequences for development and disease".

ANNE C FERGUSON-SMITH AND DEBORAH BOURC'HIS

\section{Imprinted genes in development, epigenetics and disease}

n 1984, Davor Solter (working with James McGrath at the Wistar Institute in Philadelphia) and, independently, Azim Surani (working with Sheila Barton and Michael Norris at the AFRC Institute of Animal Physiology in Cambridge) published the results of experiments on newly fertilized mouse eggs (McGrath and Solter, 1984; Surani et alo, 1984; Barton et al., 1984). They had generated embryos that contained either two sets of chromosomes inherited from the mother, or two sets of chromosomes inherited from the father. However, when transferred into pseudo-pregnant recipient females, the embryos failed to develop to term.

These remarkable results sent a clear message: despite being genetically equivalent, the set of chromosomes inherited from the mother were not functionally equivalent to the set inherited from the father. The defective development of the bi-maternal and the bi-paternal embryos indicated that, for normal development to occur, one set of chromosomes from each parent was required. This is due to a process called 'genomic imprinting' which acts in the gametes to 'mark' genes on the maternal and paternal chromosomes in order to ensure parent-of-origin specific expression after fertilization. All cells contain two copies of every gene (except those genes found on the single $Y$ chromosome in males). In general both copies of a gene are expressed. However, cells express only one copy of an imprinted gene - either the copy inherited from the father or the copy inherited from the mother. It later emerged that the imprinting marks were epigenetic modifications (in particular, DNA methylation).

Around the same time, genetic studies by Bruce Cattanach and Michael Kirk showed that imprinted genes were not evenly distributed across the whole genome but located in particular genomic regions (Cattanach and Kirk, 1985). This finding was confirmed by the subsequent identification and mapping of imprinted genes, although the first three imprinted genes, Igf2r, Igf2 and H19, were not identified until 1991 (Barlow et alo, 1991; DeChiara et alo, 1991; Ferguson-Smith et alo, 1991; Bartolomei et alo, 1991).

Over the years, studies in mice and humans have shown that imprinted genes are essential not only for the prenatal development of normal embryonic and extraembryonic components, as demonstrated in the early experiments of Surani and Solter, but also for postnatal processes that include the regulation of the brain and behavior, metabolism, and physiological adaptations (Cleaton et al., 2014). Moreover, a number of human syndromes exhibiting parent-of-origin effects in their patterns of inheritance were known, including the fetal overgrowth disorder Beckwith-Wiedemann Syndrome (which is also associated with an increased incidence of childhood tumors), and two neurological disorders (Prader-Willi Syndrome and Angelman 
Syndrome). These and other syndromes were found to be caused by the inheritance of two imprinted domains from the mother and none from the father, or vice versa; by deletions at imprinted regions; or by a failure either to establish a proper imprint during gamete production or to maintain it after fertilization.

Such studies have, of course, been important for elucidating these imprinted disorders, but perhaps more importantly, they have implicated imprinted genes more generally in pathways that control the aetiology of much more common diseases, such as those involved in growth, metabolism, cancer and neurological disorders.

We now know that genomic imprinting involves the transmission of epigenetic information, in the form of DNA methylation marks, from gametes to offspring, with the result that a set of around 100-200 genes (both protein coding genes and non-coding RNA genes) are expressed from only one of the two chromosomes in cells. The essential role for DNA methylation in imprinting was shown through the inheritance of mutations in DNA methyltransferases (Bourc'his et al., 2001; Li et al., 1993; Kaneda et al., 2004). These DNA methylation marks provide an imprint that is acted upon by a hierarchy of transcriptional and chromatin states, including differential histone modifications on the two parental chromosomes (Fournier et al., 2002), that result in the monoallelic expression of imprinted genes.

It also became clear that imprinted genes are often clustered around a single imprinting control region (ICR) that influences the monoallelic expression of the whole cluster. Indeed, ICRs are regulatory sequences that control the expression of genes that code for proteins, or for long-non-coding RNAs that control the activity of the cluster in cis. A transcription factor called CTCF also has an important role at some (but not all) of these clusters, to modulate the regulation of imprinted gene expression in a parental-origin-specific manner.

Hence, over the years, the analysis of differential DNA methylation at imprinted domains has provided a paradigm in which to assess the links between particular epigenetic states and the long- and short-range cis-acting control of gene expression in mammals. These studies have uncovered regulatory relationships between DNA methylation, histone modifications, long-non-coding RNAs and associated proteins (such as CTCF), and has helped to define many of the enzymatic processes that write, read and erase epigenetic states (Barlow and Bartolomei, 2014; FergusonSmith, 2011).

\section{Imprinted genes: a paradigm of epigenetic regulation with genetic determinism}

Where do we stand now, 34 years after the original discovery of genomic imprinting? High throughput sequencing approaches - and their application to small numbers of cells - have been instrumental in revealing the developmental regulation and extent of genomic imprinting.

In particular, genome-wide profiling of gametic methylation in mice and humans has highlighted that thousands of sequences acquire asymmetric DNA methylation states in the oocyte and spermatozoon, reflecting the contrasting biology of DNA methylation in the two germlines (Smallwood et al., 2011; Kobayashi et al., 2012). In males, sperm methylation preferentially targets intergenic sequences and transposon repeats. In females, oocyte methylation coincides with the body of actively transcribed genes, including intragenic CpG islands (Veselovska et al., 2015). The distribution and genomic properties of ICRs do not differ from these genome-wide trends: maternal ICRs all coincide with CpG island promoters located downstream of transcription start sites that are active during oocyte growth, while paternal ICRs have an intergenic location. ICRs are not established as special regulators in the germline: rather they are selected, post-fertilization, by being actively protected from the genome-wide loss of methylation that occurs before embryo implantation.

The realization that the epigenetic protection of ICRs was genetically determined came as a surprise. ICRs are endowed with several TGCCGC motifs and, when methylated, these motifs are recognized by a zinc finger protein called ZFP57 which, in turn, recruits the KAP1centered heterochromatic complex (Quenneville et al., 2011). This allows for the concentration of DNA methyltransferases around the ICRs and the propagation of their germline-methylation status in the early embryo, while the rest of the genome is undergoing global reprogramming. Upon complete depletion of ZFP57, multiple ICRs fail to maintain their 
Though we still do not understand the evolutionary processes that have led to the emergence of genomic imprinting in mammals, its interrogation over the years has revealed a wealth of epigenetic insight that continues to have an enduring influence on genome biology.

\section{Variations of imprinting in space and time}

Many genome-wide screens have been developed to identify new imprinted loci but the general conclusion is that all the canonical ICRs that is, those with parent-specific DNA methylation patterns that are maintained in a life-long and tissue-wide manner - have probably been uncovered (Xie et alo, 2012). Less robust ICRs have been detected, whereby parent-specific DNA methylation patterns are confined to early embryonic development or persist in some adult tissues only (Proudhon et al., 2012). These stage- and tissue-specific ICRs translate into variations in the allelic dosage of the imprinted genes they regulate (Greenberg et al., 2017). Biallelic expression of imprinted genes can also occur without modifying the methylation imprint itself: for example, the paternally expressed Dlk1 gene adopts biallelic expression in neural stem cells with important implications for neurogenesis (Ferrón et al., 2011). These studies have highlighted that genomic imprinting is more flexible across the lifetime of an individual than originally thought. But imprinting can also be polymorphic between mammalian species: some ICRs are found in rodents but not in humans, and vice versa (see, for example, https://atlas.genetics.kcl.ac.uk/atlas.php and www.geneimprint.com/site/genes-by-species).

As for many genetic innovations, transposons have acted as major drivers for the emergence of these species-specific ICRs. During spermatogenesis, retrotransposon methylation is guided by specific small RNAs called piRNAs (short for PIWI-interacting RNAs) to ensure that the germline genome is protected. Through this mechanism, a retrotransposon that landed into the Rasgrf1 locus in rodents has created a new paternally methylated ICR in these species (Watanabe et al., 2011). Similarly, long terminal repeat (LTR) sequences of specific retrotransposons are particularly active during oogenesis. Through their promoter activity, they can define new transcription start sites in oocytes and promote transcription-coupled DNA methylation of downstream CpG islands (Brind'Amour et al., 2018). Rodent- and human-specific insertions that contain binding sites for post-fertilization methylation maintenance (by factors such as ZFP57) can, therefore, diversify the germline 'methylome' and generate new species-specific ICRs. Furthermore, because LTR transposons are still active in rodent genomes, some ICRs are found in some mouse strains but not in others 
(Brind'Amour et al., 2018). Whether these could be phenotypically influential is unknown.

\section{Non-canonical genomic imprinting} Finally, one of the most intriguing findings of recent years was the discovery of genomic imprinting that does not involve DNA methylation. The trimethylation of lysine 27 in histone $\mathrm{H} 3$ (H3K27me3) is an epigenetic mark that is asymmetrically transmitted by parental gametes and remains after fertilization to influence the allelic expression of several genes in the early embryo (Inoue et al., 2017). However, this 'noncanonical' form of genomic imprinting is exclusively transmitted by the oocyte and is only maintained until the blastocyst stage. By the time of implantation - less than a week after fertilization - the parent-specific differences have disappeared.

Genomic imprinting was discovered at a time when the modifications to DNA and chromatin that act 'on top of' genetics and regulate genome function were only beginning to be appreciated. The contribution of this essential mammalian developmental process to our understanding of epigenetic mechanisms has been major. Through the analysis of active and repressed alleles of imprinted genes within a given cell type during development, robust relationships between regional epigenetic control and transcriptional behavior have been established. Though we still do not understand the evolutionary processes that have led to the emergence of genomic imprinting in mammals, its interrogation over the years has revealed a wealth of epigenetic insight that continues to have an enduring influence on genome biology.

Anne C Ferguson-Smith is in the Department of Genetics, University of Cambridge, Cambridge, United Kingdom

afsmith@mole.bio.cam.ac.uk

Deborah Bourc'his is in the Genetics and Developmental Biology Department, Institut Curie, Paris, France

Deborah.Bourchis@curie.fr

(iD) https://orcid.org/0000-0001-9499-7291

Competing interests: The authors declare that no competing interests exist.

Published 22 October 2018

\section{References}

Barlow DP, Stöger R, Herrmann BG, Saito K, Schweifer N. 1991. The mouse insulin-like growth factor type-2 receptor is imprinted and closely linked to the Tme locus. Nature 349:84-87. DOI: https://doi. org/10.1038/349084a0, PMID: 1845916 Barlow DP, Bartolomei MS. 2014. Genomic imprinting in mammals. Cold Spring Harbor Perspectives in Biology 6:a018382. DOI: https://doi.org/10.1101/ cshperspect.a018382, PMID: 24492710

Bartolomei MS, Zemel S, Tilghman SM. 1991. Parental imprinting of the mouse $\mathrm{H} 19$ gene. Nature 351:153155. DOI: https://doi.org/10.1038/351153a0, PMID: 1709450

Barton SC, Surani MA, Norris ML. 1984. Role of paternal and maternal genomes in mouse development. Nature 311:374-376. DOI: https://doi. org/10.1038/311374a0, PMID: 6482961

Bourc'his D, Xu GL, Lin CS, Bollman B, Bestor TH. 2001. Dnmt3L and the establishment of maternal genomic imprints. Science 294:2536-2539.

DOI: https://doi.org/10.1126/science.1065848, PMID: 11719692

Brind'Amour J, Kobayashi H, Richard Albert J, Shirane K, Sakashita A, Kamio A, Bogutz A, Koike T, Karimi MM, Lefebvre L, Kono T, Lorincz MC. 2018. LTR retrotransposons transcribed in oocytes drive speciesspecific and heritable changes in DNA methylation. Nature Communications 9:3331. DOI: https://doi.org/ 10.1038/s41467-018-05841-x, PMID: 30127397 Cattanach BM, Kirk M. 1985. Differential activity of maternally and paternally derived chromosome regions in mice. Nature 315:496-498. DOI: https://doi. org/10.1038/315496a0, PMID: 4000278

Cleaton MA, Edwards CA, Ferguson-Smith AC. 2014 Phenotypic outcomes of imprinted gene models in mice: elucidation of pre- and postnatal functions of imprinted genes. Annual Review of Genomics and Human Genetics 15:93-126. DOl: https://doi.org/10. 1146/annurev-genom-091212-153441, PMID: 24 898037

DeChiara TM, Robertson EJ, Efstratiadis A. 1991. Parental imprinting of the mouse insulin-like growth factor II gene. Cell 64:849-859. DOI: https://doi.org/ 10.1016/0092-8674(91)90513-X, PMID: 1997210 Eggermann T, Perez de Nanclares G, Maher ER, Temple IK, Tümer Z, Monk D, Mackay DJ, Grønskov K, Riccio A, Linglart A, Netchine I. 2015. Imprinting disorders: a group of congenital disorders with overlapping patterns of molecular changes affecting imprinted loci. Clinical Epigenetics 7:123. DOI: https:// doi.org/10.1186/s13148-015-0143-8, PMID: 26583054 Ferguson-Smith AC, Cattanach BM, Barton SC, Beechey CV, Surani MA. 1991. Embryological and molecular investigations of parental imprinting on mouse chromosome 7. Nature 351:667-670.

DOI: https://doi.org/10.1038/351667a0, PMID: 20520 93

Ferguson-Smith AC. 2011. Genomic imprinting: the emergence of an epigenetic paradigm. Nature Reviews Genetics 12:565-575. DOI: https://doi.org/10. 1038/nrg3032, PMID: 21765458

Ferrón SR, Charalambous M, Radford E, McEwen K, Wildner H, Hind E, Morante-Redolat JM, Laborda J, Guillemot F, Bauer SR, Fariñas I, Ferguson-Smith AC. 2011. Postnatal loss of Dlk1 imprinting in stem cells and niche astrocytes regulates neurogenesis. Nature 475:381-385. DOI: https://doi.org/10.1038/

nature10229, PMID: 21776083

Fournier C, Goto Y, Ballestar E, Delaval K, Hever AM, Esteller M, Feil R. 2002. Allele-specific histone lysine 
methylation marks regulatory regions at imprinted mouse genes. EMBO Journal 21:6560-6570. DOI: https://doi.org/10.1093/emboj/cdf655, PMID: 12456662

Greenberg MV, Glaser J, Borsos M, Marjou FE, Walter M, Teissandier A, Bourc'his D. 2017. Transient transcription in the early embryo sets an epigenetic state that programs postnatal growth. Nature Genetics 49:110-118. DOI: https://doi.org/10.1038/ng.3718, PMID: 27841881

Inoue A, Jiang L, Lu F, Suzuki T, Zhang Y. 2017. Maternal H3K27me3 controls DNA methylationindependent imprinting. Nature 547:419-424.

DOI: https://doi.org/10.1038/nature23262, PMID: 2 8723896

Kaneda M, Okano M, Hata K, Sado T, Tsujimoto N, Li E, Sasaki H. 2004. Essential role for de novo DNA methyltransferase Dnmt3a in paternal and maternal imprinting. Nature 429:900-903. DOl: https://doi.org/ 10.1038/nature02633, PMID: 15215868

Kawahara M, Wu Q, Takahashi N, Morita S, Yamada K, Ito M, Ferguson-Smith AC, Kono T. 2007. Highfrequency generation of viable mice from engineered bi-maternal embryos. Nature Biotechnology 25:10451050. DOI: https://doi.org/10.1038/nbt1331, PMID: 17704765

Kobayashi H, Sakurai T, Imai M, Takahashi N, Fukuda A, Yayoi O, Sato S, Nakabayashi K, Hata K, Sotomaru Y, Suzuki Y, Kono T. 2012. Contribution of intragenic DNA methylation in mouse gametic DNA methylomes to establish oocyte-specific heritable marks. PLoS Genetics 8:e1002440. DOI: https://doi.org/10.1371/ journal.pgen.1002440, PMID: 22242016

Li E, Beard C, Jaenisch R. 1993. Role for DNA methylation in genomic imprinting. Nature 366:362365. DOI: https://doi.org/10.1038/366362a0, PMID: 8247133

Li X, Ito M, Zhou F, Youngson N, Zuo X, Leder P, Ferguson-Smith AC. 2008. A maternal-zygotic effect gene, Zfp57, maintains both maternal and paternal imprints. Developmental Cell 15:547-557.

DOI: https://doi.org/10.1016/j.devcel.2008.08.014, PMID: 18854139

McGrath J, Solter D. 1984. Completion of mouse embryogenesis requires both the maternal and paternal genomes. Cell 37:179-183. DOI: https://doi. org/10.1016/0092-8674(84)90313-1, PMID: 6722870 Proudhon C, Duffié R, Ajjan S, Cowley M, Iranzo J, Carbajosa G, Saadeh H, Holland ML, Oakey RJ, Rakyan VK, Schulz R, Bourc'his D. 2012. Protection against de novo methylation is instrumental in maintaining parent- of-origin methylation inherited from the gametes. Molecular Cell 47:909-920. DOI: https://doi.org/10. 1016/j.molcel.2012.07.010, PMID: 22902559

Quenneville S, Verde G, Corsinotti A, Kapopoulou A, Jakobsson J, Offner S, Baglivo I, Pedone PV, Grimaldi G, Riccio A, Trono D. 2011. In embryonic stem cells, ZFP57/KAP1 recognize a methylated hexanucleotide to affect chromatin and DNA methylation of imprinting control regions. Molecular Cell 44:361-372.

DOI: https://doi.org/10.1016/j.molcel.2011.08.032, PMID: 22055183

Schulz R, Proudhon C, Bestor TH, Woodfine K, Lin CS, Lin SP, Prissette M, Oakey RJ, Bourc'his D. 2010. The parental non-equivalence of imprinting control regions during mammalian development and evolution. PLoS Genetics 6:e1001214. DOI: https://doi.org/10.1371/ journal.pgen.1001214, PMID: 21124941 Smallwood SA, Tomizawa S, Krueger F, Ruf N, Carli N, Segonds-Pichon A, Sato S, Hata K, Andrews SR, Kelsey G. 2011. Dynamic CpG island methylation landscape in oocytes and preimplantation embryos. Nature Genetics 43:811-814. DOI: https://doi.org/10 1038/ng.864, PMID: 21706000

Surani MA, Barton SC, Norris ML. 1984. Development of reconstituted mouse eggs suggests imprinting of the genome during gametogenesis. Nature 308:548550. DOl: https://doi.org/10.1038/308548a0, PMID: 6709062

Veselovska L, Smallwood SA, Saadeh H, Stewart KR, Krueger F, Maupetit-Méhouas S, Arnaud P, Tomizawa S, Andrews S, Kelsey G. 2015. Deep sequencing and de novo assembly of the mouse oocyte transcriptome define the contribution of transcription to the DNA methylation landscape. Genome Biology 16:209. DOI: https://doi.org/10.1186/s13059-015-0769-z, PMID: 26408185

Watanabe T, Tomizawa S, Mitsuya K, Totoki Y, Yamamoto Y, Kuramochi-Miyagawa S, lida N, Hoki Y, Murphy PJ, Toyoda A, Gotoh K, Hiura H, Arima T, Fujiyama A, Sado T, Shibata T, Nakano T, Lin H, Ichiyanagi K, Soloway PD, et al. 2011. Role for piRNAs and noncoding RNA in de novo DNA methylation of the imprinted mouse Rasgrf1 locus. Science 332:848852. DOI: https://doi.org/10.1126/science.1203919, PMID: 21566194

Xie W, Barr CL, Kim A, Yue F, Lee AY, Eubanks J, Dempster EL, Ren B. 2012. Base-resolution analyses of sequence and parent-of-origin dependent DNA methylation in the mouse genome. Cell 148:816-831. DOI: https://doi.org/10.1016/j.cell.2011.12.035, PMID: 22341451 